\begin{tabular}{c}
\hline Review of \\
ECONOMICS \\
and \\
INSTITUTIONS
\end{tabular}

\title{
Contract Renewal as an Incentive Device. An Application to the French Urban Public Transport Sector
}

\author{
Axel Gautier ${ }^{\bowtie}$ \\ University of Liege (ULg), \\ HEC Management School
}

\author{
Anne Yvrande-Billon \\ CES, University Paris 1
}

\begin{abstract}
French urban public transport industry, operations are often delegated and periodically put out for tender. Thus, operators' incentives to reduce costs come from both profit maximization during the current contract and from the perspective of contract renewal. We construct a dynamic incentive regulation model that captures these features and we show that both the level of cost-reducing effort and its repartition during the contracting period depend on the contract type (cost-plus, gross cost or net cost contract). We then estimate a cost frontier model for an eight-year panel of French bus companies (664 company-year observations) to test our predictions.
\end{abstract}

JEL classification: L33; L51; L92

Keywords: incentive regulation, urban public transport, stochastic frontier analysis, competition for contract, contract renewal

We would like to thank Sergio Perelman, Stéphane Saussier, Steven Tadelis, Joe Tharakan, Vanessa Valero and participants to the 3rd International Conference on Funding Transport Infrastructure (Paris, June 2008), Journées de microéconomie appliquée (Dijon, June 2009) and EARIE (Ljubljana, September 2009) for their fruitful comments on an earlier version of the paper. The usual disclaimer applies.

$\square$ Address: University of Liege (ULg), HEC Management School, BAT B31, Bd du Rectorat 7, 4000 Liege, Belgium. (Phone: +324 366. 30.53, Fax: +32 4 366.93. 18, E-mail: agautier@ulg.ac.be).

\section{Recommended Citation}

Gautier, A., Yvrande-Billon, A. (2013). Contract Renewal as an Incentive Device. An Application to the French Urban Public Transport Sector. Review of Economics and Institutions, 4(1), Article 2. doi: 10.5202/rei.v4i1.88. Retrieved from http://www.rei.unipg.it/rei/article/view/88 


\section{Introduction}

In a context of severe public budget constraints, the financial distress of the urban public transport sector has led many European countries to implement significant reforms. These organizational and regulatory changes, encouraged by the European Commission 11 consist in outsourcing service operation to private operators and awarding public service contracts by means of competitive procedures. In addition, such reforms are usually combined with the introduction of incentive mechanisms in the contracts.

Our objective in this paper is to evaluate the impact of both competition for the market and contractual incentive schemes on the performance of local public transport firms. More precisely, our aim is to investigate, theoretically and empirically, to what extent the perspective of contract renewal and the type of regulatory contract influence the operators' incentives to reduce their operating costs. For that purpose, we study the French bus transport sector, which has a long experience in delegated management and competitive tendering, and we use a stochastic cost frontier approach that allows one to define the unobservable inefficiency as a function of exogenous variables.

Few empirical papers have shown the role played by regulatory schemes on cost efficiency in the transport sector (Gagnepain and Ivaldi, 2002a; Piacenza, 2006; Margari et al. 2007) and, to the best of our knowledge, only one has analyzed the dynamic effect on performance of the various types of contracts (Dalen and Gomez-Lobo, 2003).

The present paper then contributes to the literature on three counts. First, because of the variety of contractual practices used in the French public transport system, we are able to use a sophisticated classification of regulatory schemes, which distinguishes between cost-plus, gross-cost and netcost contracts. To our knowledge, the impact of these three categories of contracts on cost efficiency has never been assessed because previous studies were restricted to the binary typology opposing cost-plus and fixed-price contracts. Second, the long tradition of competitive tendering in France provides great opportunity to evaluate whether competition for the field effectively acts as an incentive device. In many other countries, reforms are too recent to estimate the incidence of competitive tendering. Third, the original dynamic model of incentive regulation we provide and the large set of data we use (unbalanced panel of 664 yearly observations covering 111 different urban transport networks from 1995 to 2002) allow us to investigate whether the effort path (the allocation of cost-reducing effort over the contracting period) varies with the type of regulatory scheme.

The paper is organized as follows. Section 2 describes the French urban public transport sector. Section 3 presents our model of dynamic regulation

${ }^{1}$ In particular, Regulation (EC) No 1370/2007 of the European Parliament and of the Council of 23 October 2007 on public passenger transport services by rail and by road. 
and the propositions we intend to test. Sections 4 and 5 present our methodology and data. Section 6 provides the results of our estimations. Section 7 concludes and highlights the implications for regulatory policy.

\section{The French Urban Public Transport Sector}

In France, public transport services are organized by local governments (cities or groups of cities) and there are 241 independent public transport networks. Each local government is in charge of the organization and the regulation of its own urban public transport system and different contractual and ownership structures are available.

\subsection{Ownership Structure}

Local governments have to choose between direct provision and outsourcing. In the former option, urban transport services are provided inhouse by a public administration. ${ }^{2}$ In the latter case, the local government delegates the service provision to an external contractor that is either a private company or a mixed company: $]^{3}$ For Amaral and Yvrande-Billon (2009), the decision to use external providers rather than internal production is dictated by political and economic motives (mainly service complexity) while the choice between a mixed company and a private one is mainly based on political economy determinants such as the level of income inequalities or the organizational choices made by neighboring cities as regard transport services but also other utilities.

\subsection{Contracts}

When local governments outsource public transport provision, the service and its financing are organized within the framework of a fixed-term regulatory contract. This contract specifies the characteristics of the services to be offered (route structure, quality, fares, timetable, special service...), the resources at disposal of the contractor and a compensation rule.

The local authority put at disposal of the designed contractor transferable resources such as staff (mainly bus drivers), vehicles, building and depots. Indeed, in most of the cases, the organizing authority is the owner of the vehicle fleet (in 2009, 89\% of the bus fleet was owned by local governments; GART, 2009) and strategic decisions such as the investments in infrastructure and in rolling stock remain under her entire responsibility. At the end of the contract, these resources remain within the local authority.

2 In France, approximately $10 \%$ of the networks are operated by a public company.

3 In this mixed ownership regime, the majority of the capital stock of the company (at least $51 \%$ and at most $85 \%$ ) is under public control (usually a local authority) and at least $15 \%$ of the capital stock is owned by one or several private companies. 
With delegated service provision, private operators are in charge of the day-to-day management of the local transport services which encompasses, for instance, staff management (including hiring decisions), bus and drivers scheduling, choice of subcontractors, vehicle utilization, promotion of public transports. To this end, they combine the resources provided by the local authority with their own, mainly managerial staff and expertise. Private contractors effectively manage the local transport company during the term of the contract but they lack control on some long-term decisions such as renewal of the bus fleet that remain within the hand of the local authority.

Various contractual schemes are used to regulate the financial relations between external operators and the local authority. Indeed, when service operation is delegated to a private or mixed firm, the formal contract between local authorities and operators may be of four different types: costplus (called management contract), gross cost, net cost and concession contracts. These contracts differ in their degree of risk-sharing.

In the cost-plus contract, the local authorities collect the traffic receipts and fully reimburse the production cost of the operators increased by some pre-specified amount (the 'plus'). This contract is risk-free for the operators as profits are independent of the realized revenues and costs. In the gross-cost contract, the traffic receipts are still collected by the authorities but the transfer to the operators is specified ex-ante. Thus, any cost increase or decrease directly affects the operators' profit. Hence, with a gross cost contract, the operators are responsible for the production risk. With a net cost contract, the operators collect the traffic receipts and receive, in addition, a fixed transfer from the local authorities. ${ }^{4}$ The operators are thus responsible for both the production risk (on costs) and the commercial risk (on revenues). In the concession contract that is used in a limited number of municipalities, the operators bear the industrial and commercial risks, as in net cost contracts, but they are also in charge of the investments in dedicated infrastructure, equipment and rolling stock. This type of contract is therefore associated with longer duration but is rarely used in the French context.

In our econometric model, we will assume that the choice of a particular contract type by the organizing authority is independent of the network's economic characteristics. This hypothesis is commonly accepted and is supported by empirical evidence. Indeed, concentrating on the eighties, Caillaud and Quinet (1993) show that the growing use of net cost contracts is better explained by historical reasons than by economic motivations. In the same vein, Gagnepain and Ivaldi (2002a), focusing on the 1985-1993 period, demonstrate that regulatory schemes can reasonably be assumed to be exogenous.

\footnotetext{
${ }^{4}$ In the French urban transport system, commercial receipts cover in average less than $30 \%$ of the total operating costs, hence operators are heavily subsidized (UTP, 2009).
} 


\subsection{Contract Attribution and Renewal}

When the service is delegated, local authorities are obliged to periodically organize a competitive tendering to select the service provider, on average every 6 years. In this case, firms compete for the management of the local public transport company. The use of competitive tendering to select the service provider is compulsory and automatic renewal of contracts is forbidden. But competition for the market is limited (Yvrande-Billon, 2006 and Amaral et al. 2009): There are usually few bidders (1.6 in average over the period 1995-2002 which is the one we concentrate on) and a high proportion of tenders with only one bidder ( $50 \%$ in average). Additionally, out of the 99 bidding procedures we were able to record over the 1995-2002 period, $87 \%$ (85) have led to the renewal of the incumbent. Interestingly, we also observe that, when the incumbent is a mixed company, he is renewed in $95.45 \%$ of the cases. ${ }^{5}$ whereas a private incumbent has a $83.12 \%$ probability of being renewed $]^{6}$

These results need to be interpreted carefully. The decreasing and low number of bidders might obviously be related to the extension of the networks and to the resulting concentration of the transport industry. The market is dominated by three large companies that, together, operate more than $74 \%$ of the networks. The potential for competition is therefore limited de facto.

Furthermore, the rate of incumbents' renewal is likely to be a very imperfect indicator of competitive pressure. We can indeed consider that the incumbents have renewed most of their contracts by placing better bids than their competitors. In this sense, the high rate of incumbents' renewal that we observe in France would not indicate that competition for the market does not exist.

However, given the very high proportion of calls for tender that received only one bid and considering that collusive practices in the sector were recently condemned by the French Competition Commission (Conseil de la Concurrence, 2005), one can rightly assert that the French urban public transport sector is characterized by a low level of competition.

In addition, the French system is prone to favoritism. Contracts are attributed to the operator that offers the best economic value for the service meaning that factors other than the cost are taken into account.? Local authorities, that monitor the selection procedure, thus have an important discretionary power. Moreover, as argued in several papers, the procedure lacks transparency (Desrieux et al. 2010).

The low level of competitive intensity suggests that contract renewal de-

\footnotetext{
5 During the sample period, there were 22 calls for tenders for the management of a mixed company and only one resulted in a change of operator.

6 During the sample period, there were 77 calls for tenders for the management of a private company and 13 resulted in a change of operator.

7 See Yvrande-Billon (2006) for a detailed explanation of the procedure.
} 
cisions might be relatively insensitive to the realized performance. And, consistently with our previous observations, this should be particularly the case for mixed companies, which are partly managed by local authorities. Indeed, in a mixed company, the authority is both involved in the management of one potential bidder and responsible for allocating the contract. In such a situation, rival firms might be deterred from making counter-offers and the incumbent's renewal is likely. $]^{8}$

On the other hand, the discretion left to the local government implies that the reputation of the contractor in place might be important in the decision to renew a contract (Iossa and Rey, 2009). Thus, even if competition is limited, better performances may substantially increase the renewal probability of the contractor and provide incentives for the firm. Our theoretical and empirical models aim to verify the importance of contract renewal as an incentive device.

\section{Theoretical Model}

\subsection{Cost-Plus and Gross Cost Contracts}

We construct a continuous time dynamic model of incentive regulation. At time $t=0$, the regulator and the firm sign a contract that lasts until time $\mathrm{T}$, the expiration date. The contract stipulates the duties of the contractor and a compensation scheme. We consider (1) a cost-plus contract where the regulator reimburses at each time $t$, the contractor's cost $c(t)$ increased by a given amount $p^{C+}$, and (2) a gross-cost contract where the regulator transfers $p^{G C}$ to the firm at each time $\mathrm{t}$ irrespective of its realized cost $c(t)$. In both cases, the traffic receipts are collected by the regulator.

The cost $c(t)$ depends on the accumulated effort exerted by the firm and the realization of a stochastic variable $\varepsilon(t)$. In line with the incentive regulation literature (Laffont and Tirole, 1993), the cost $c(t)$ is observable but the cost generating process is not.

By exerting an unobservable effort $a(t)$ at time $t$, the firm reduces its cost by an amount $a(t)$. That is $\dot{c}=-a(t)$ where $\dot{c}$ is the time derivative of $c(t)$. Hence, we have:

$$
c(t)=c(0)-\int_{0}^{t} e^{r(t-\tau)} a(\tau) d \tau+\varepsilon(t)
$$

The parameter $r$ measures the accumulative nature of the effort. When $r=0$, an effort $a(t)$ leads to a permanent cost reduction; when $r>0$, effort

\footnotetext{
8 Such effects are highlighted by the local authorities themselves: in recent interviews conducted by a trade organization (GART, 2005), some of them declared that delegation to a mixed company was a mode of organization that discourages potential entrants to submit bids.
} 
accumulation is only partial i.e. the impact of an effort $a(t)$ dissipates over time. In the urban transport sector, initiatives such as effort to achieve fuel efficiency, network gridding, adoption of cost-reducing innovations or improved staff management are examples of accumulative effort and without loss of generality, we assume that $r=0$.

Effort is costly: when the firm exerts an effort $a(t)$, it incurs a cost $\psi(a(t))$. The function $\psi($.$) satisfies \psi^{\prime}>0, \psi^{\prime \prime}>0, \psi(0)=0, \psi^{\prime}(0)=0$. The stochastic variable $\varepsilon(t)$ is a white noise with zero mean. Denote by $\bar{c}(t)=$ $c(0)-\int_{0}^{t} a(\tau) d \tau$, the expected cost of the firm at date $\mathbf{t}$, the firm's expected profit can be written as:

$\bar{\pi}(t)=\left\{\begin{array}{l}p^{C+}-\psi(a(t)) \text { if the firm operates under a cost - plus contract } \\ p^{G C}-\bar{c}(t)-\psi(a(t)) \text { if the firm operates under a gross cost contract }\end{array}\right.$

At the expiration of the initial contract (at time T), a new contract ${ }^{9}$ starts and the perspective of contract renewal may be an important source of incentives for the incumbent firm. Indeed, the role of contract renewal as an incentive device has long been recognized (Laffont and Tirole, 1993; Dalen et al. 2006; Iossa and Rey, 2009). ${ }^{10}$

In this paper, we assume that the decision of being renewed (or not) at $\mathrm{T}$ depends on the last period cost $c(T)$. We denote by $P(c(T))$ the probability of renewal for the incumbent when it achieves a cost $c(T)$ at time T and assume that $P(c(T))$ is continuous, differentiable and satisfies $P^{\prime}=d P(c(T)) / d<0$. That is, a firm with a lower cost has a higher probability of being renewed.11

If the contract of the incumbent firm is renewed for a period $\Delta T$, the firm collects an additional profit flow that has a discounted value equaled to $\bar{\pi}$. This amount is independent of the contract type ${ }^{12}$ and of the realized cost $c(T) 13$

The firm maximizes the sum of its current and future expected profit flows. Profits from the current contract are discounted at rate $\rho$. That is, the firm solves the following problem:

9 This contract may differ from the previous contract in many respects (length, type of compensation, duties of the firm...).

${ }^{10}$ In Laffont and Tirole (1993), the renewal policy is part of the regulatory contract and the regulator may, for incentive reasons, bias the contract renewal to favor the incumbent or the entrant.

${ }^{11}$ In this model, we use a formulation where the probability of being renewed depends on the last period cost exclusively. Alternatively, we can consider that the probability of being renewed depends on a weighted average of the cost with last period cost receiving more weights. This alternative formulation would not change qualitatively our results.

${ }^{12}$ There is no reason to consider that there exists a contract type that pays systematically more than another.

${ }^{13}$ If, in the case the contract is renewed, more efficient firms have a lower profit flow, by exerting effort the operator increases its probability of contract renewal but it decreases the profit coming from contract renewal. Therefore, incentives coming from contract renewal are lower (a kind of ratchet effect). 


$$
\max _{a(t)} \int_{0}^{T} e^{-\rho t} \bar{\pi}(t) d t+P(\bar{c}(T)) \bar{\pi} \text { subject to } \dot{c}=-a(t), c(0) \text { and } T \text { given. }
$$

Using optimal control theory, we can derive the optimal effort path $\hat{a}(t)$ for each type of contract.

Proposition 1 With a cost-plus contract, the effort path is given by

$$
\hat{a}^{C+}(t)=\psi^{\prime-1}\left(-\frac{P^{\prime} \bar{\pi}}{e^{-\rho t}}\right)
$$

and $\hat{a}^{C+}(t)$ is increasing over time: $d \hat{a}^{C+}(t) / d t>0$.

The only source of incentives for the firm with a cost-plus contract is the perspective of contract renewal, which requires a good performance at the end of the contracting period. The firm decides on a cost target $c(T)$ and spreads the necessary effort over the contracting period. The resulting effort path is increasing because the discounted cost of effort decreases over time, i.e. a given effort is less costly if exerted latter. And this effect will be exacerbated if effort is only partially cumulative $(r>0)$. With a cost-plus contract, the effort increases and the operating cost decreases when the expiration date approaches. The rate of increase in the effort path depends on the discount factor. A firm that values the future a lot (a low $\rho$ ) has a slightly increasing effort path and the slope would be higher for a more impatient firm.

Proposition 2 With a gross cost contract, the effort path is given by

$$
\hat{a}^{G C}(t)=\psi^{\prime-1}\left(-\frac{P^{\prime} \bar{\pi}}{e^{-\rho t}}+\frac{1}{\rho}\left(1-\frac{e^{-\rho T}}{e^{-\rho t}}\right)\right)
$$

With a gross cost contract, there is an additional source of incentive: the profit flow from the current contract. And, with a cumulative effort, the benefit of a given effort is higher when it is exerted earlier. The maximization of the current profit flow calls for a decreasing effort path. At the same time, the perspective of contract renewal calls for an increasing effort path. Thus, the combination of the two sources of incentives might lead to an increasing, decreasing or U-shaped effort path but, in any case, the firm's expected cost is decreasing during the contract.

Comparing the two effort paths, we have that, at any time, the effort is higher with the gross cost contract than with the cost-plus contract, a standard result in the incentive literature (Laffont and Tirole, 1993; Bajari and Tadelis, 2001) and largely confirmed by empirical evidence (for instance Gagnepain and Ivaldi, 2002a; Roy and Yvrande-Billon, 2007 for the French urban transport sector). 
Proposition 3 At each time $t<T, \hat{a}^{G C}(t)>\hat{a}^{C+}(t)$.

Finally, the competitiveness of the contract attribution process that can be measured by the sensitivity of the renewal probability with respect to performance determines the incentives provided by the contract renewal process. Non-surprisingly, when a better performance has a limited impact on the renewal decision (a low $P^{\prime}$ ), for instance because competition for the contract is limited, incentives are lower. This would be the case for mixed companies as, according to our observations, the contract attribution process is not competitive at all i.e. characterized by a low $P^{\prime}$.

Proposition 4 The efforts $\hat{a}^{C+}(t)$ and $\hat{a}^{G C}(t)$ increase with $P^{\prime}$.

\subsection{Gross Cost and Net Cost Contracts}

In the public transport sector, there is a third popular contract type: the net cost contract, where the operator receives a fixed payment and collects the commercial revenues.

The total income at period $t$ for an operator regulated by a net cost contract is then $\bar{p} x(t)+p^{N C}$ where $p^{N C}$ is the transfer, $\bar{p}$ is the service price (the fare) and $x(t)$ is the quantity sold. In the public transport sector, prices are regulated and the only way to increase sales is to increase traffic volume.

The demand for services depends on the price, the quality and the commercial effort performed to promote the service. In the field of urban transport, this commercial effort includes all the initiatives to encourage the use of public transport (information to potential customers, mobility plans, advertisement, and provision of intermodal facilities).

We therefore distinguish productive and commercial efforts. Productive effort $a_{1}(t)$ aims at reducing the cost: $\dot{c}=-a_{1}(t)$; commercial effort $a_{2}(t)$ aims at increasing the quantity sold: $\dot{x}=f\left(a_{2}(t)\right)$ and $f^{\prime}>0$. With a net cost contract, renewal decision at date $T$ is based on the firm's financial performance measured by the operating deficit $c(T)-\bar{p} x(t) \geq 0$.

Suppose that productive and commercial efforts are substitute. This raises the idea that managerial resources are scarce and, therefore, more effort in one task makes, at the margin, effort more costly in the other. Hence we can establish that (see Appendix A for details):

Proposition 5 (a) Firms operating under a gross cost contract exert more productive effort than firms operating under a net cost contract. (b) Firms operating under a net cost contract perform commercial effort while firms operating under a gross cost contract do not.

A net cost contract provides less incentive for productive efficiency than 
a gross cost contract because commercial effort partially crowds out productive effort. Firms operating under a net cost contract will divide their effort between commercial and productive tasks, while those operating under a gross cost will focus exclusively on productive tasks. The gross cost contract provides strong incentives for cost efficiency but nothing beyond that. In particular, the commercial efforts could be neglected if increasing traffic is more costly. On the contrary, the net cost contract provides less incentive for cost-minimizing effort but it forces the operator to take into account all the dimensions of the services including commercial aspects. Accordingly, firms regulated by a gross cost contract should have a lower cost than those regulated by a net cost contract.

\section{Empirical Model}

\subsection{A Stochastic Cost Frontier Approach}

To test our propositions, we estimate, for each year, the cost inefficiency of each external public transport operator. The cost inefficiency is a measure of the distance between the cost frontier and the actual cost. As explained in our theoretical model, more effort reduces the operator's cost and moves the firm closer to the cost frontier. Thus by exerting effort, the firm reduces its cost inefficiency. This approach has been adopted in various empirical contributions (Aubert and Reynaud, 2005; Piacenza, 2006; Margari et al. 2007; Cambini et al. 2007).

Several methods can be used to evaluate the cost efficiency of a given firm (Murillo-Zamorano, 2004). Among the more common approaches, ${ }^{14}$ the one we use is the stochastic frontier analysis (SFA). This frontier method is not strictly preferable to the others. On the one hand, compared to the non-parametric methods, this method allows taking account of random errors. On the other hand, its main disadvantage is that it assumes that the boundary of the cost frontier can be represented by a particular functional form with constant parameters. However, we consider that the fact that SFA imposes an explicit functional form and distribution assumption on data is less of an issue since our large database allows us to run a translogarithmic function, which is well known for its flexibility properties. Moreover, as our objective in this paper is not only to estimate a cost frontier and collect inefficiency scores but also and above all to analyze the determinants of cost inefficiency, the more relevant method seems to be the stochastic frontier analysis and more precisely, the panel model proposed by Battese and Coelli (1995).

${ }^{14}$ The three more common approaches are (1) parametric linear programming approach, (2) data envelopment analysis and (3) stochastic production frontier. For a description of these different approaches, see Coelli et al. (1998) or Coelli et al. (2003). 
The stochastic cost frontier of a network operator $i$ in time $t$ is thus defined by: $V C_{i t}=V C\left(Y_{i t}, X_{i t} ; \beta\right)+v_{i t}+u_{i t}$, where $V C_{i t}$ represents the variable cost of production of the $i$-th firm at date $t ; Y_{i t}$ is a measure of the output produced by the $i$-th firm at date $t ; X_{i t}$ is a vector of variable input prices and $\beta$ is a vector of unknown parameters to be estimated. The $v_{i t}$ and $u_{i t}$ are random variables. More precisely, $v_{i t}$ is the idiosyncratic error component of the stochastic part. It corresponds to the usual disturbance introduced in regression models, and therefore represents all types of omitted or unobservable variables that have unbounded effects on cost (such as weather uncertainty or measurement errors). $u_{i t}$ is the cost inefficiency component of the stochastic part. It is therefore supposed to be a non-negative valued random variable $\left(u_{i t} \geq 0\right)$ capturing the technical and economic inefficiency under control of the operator and it is assumed that inefficiency could be reduced by exerting effort.

The $v_{i t}$ are assumed to be $i i d \sim N\left(0, \sigma_{v}{ }^{2}\right)$ random errors, independently distributed of the $u_{i t}$. The $u_{i t}$ are assumed to be independently distributed as truncated normal $N\left(W_{i t} \delta, \sigma_{u}^{2}\right)$, where $W_{i t}$ is a vector of explanatory variables that affect cost inefficiency of firms over time and $\delta$ is a vector of unknown coefficients.

The parameters $\beta$ and $\delta$ are estimated simultaneously with the method of maximum likelihood and the likelihood function is expressed in terms of the variance parameters, $\sigma^{2}=\sigma_{u}^{2}+\sigma_{v}^{2}$ and $\gamma^{2}=\sigma_{u}^{2} /\left(\sigma_{u}^{2}+\sigma_{v}^{2}\right) . \gamma$ measures the importance of the variance of cost inefficiency relative to total variance. A value close to one indicates that cost inefficiency is relatively important to the random noise term affecting cost level (for a more detailed explanation of this method, see Kumbhakar and Knox Lovell, 2000).

A first advantage of the Battese and Coelli's model is that it formulates a model for the cost inefficiency effects, which is not done in many studies estimating stochastic cost frontiers. The second advantage is that it allows the parameters of the stochastic cost frontier and those of the inefficiency model to be estimated simultaneously. Therefore, this approach is statistically more relevant than the two-stage approach used in several studies which consists in predicting the technical inefficiency effects via the estimation of a stochastic production frontier and then regressing the inefficiency measures obtained in the first stage on some explanatory variables. Thus, in the first stage, inefficiency effects are assumed to be identically distributed whereas in the second stage these error terms are assumed to depend on some other variables. The model developed by Battese and Coelli enables this inconsistency to be avoided (Dalen and Gomez-Lobo, 2003). 


\subsection{Specifying a Cost Function for Urban Public Transport}

Most of the cost models for the urban transport sector ${ }^{15}$ distinguish four categories of input for production: (1) capital, (2) labor, (3) operating expenses (material) and (4) a residual input (overhead). The variable cost of production, $V C$, is defined as the sum of labor, materials and overhead expenses. Indeed, the capital input $K$, measured by the rolling stock fleet (i.e. the total number of buses in each network's fleet), is considered to be a fixed input in the short-run since it is owned by public authorities and related to their financing program.

Due to its well-known flexibility properties, we estimate a translogarithmic cost function defined for each network operator at each period by:

$$
\begin{aligned}
\ln \left(\frac{V C}{P_{S}}\right) & =\beta_{0}+\beta_{Y} \ln Y+\beta_{N} \ln N+\beta_{S P} \ln S P+\beta_{A G E} \ln A G E+\beta_{K} \ln K \\
& +\sum_{j} \beta_{j} \ln \hat{P}_{j}+\beta_{Y, N} \ln Y \ln N+\beta_{Y, S P} \ln Y \ln S P+\beta_{Y, A G E} \ln Y \ln A G E \\
& +\beta_{Y, K} \ln Y \ln K+\sum_{j} \beta_{Y, j} \ln Y \ln \hat{P}_{j}+\beta_{N, S P} \ln N \ln S P+\beta_{N, A G E} \ln N \ln A G E \\
& +\beta_{N, K} \ln N \ln K+\sum_{j} \beta_{N, j} \ln N \ln \hat{P}_{j}+\beta_{S P, A G E} \ln S P \ln A G E+\beta_{S P, K} \ln S P \ln K \\
& +\sum_{j} \beta_{S P, j} \ln S P \ln \hat{P}_{j}+\beta_{A G E, K} \ln A G E \ln K+\sum_{j} \beta_{A G E, j} \ln A G E \ln \hat{P}_{j} \\
& +\frac{1}{2} \beta_{Y, Y}(\ln Y)^{2}+\frac{1}{2} \beta_{N, N}(\ln N)^{2}+\frac{1}{2} \beta_{S P, S P}(\ln S P)^{2}+\frac{1}{2} \beta_{A G E, A G E}(\ln A G E)^{2} \\
& +\frac{1}{2} \beta_{K, K}(\ln K)^{2}+\frac{1}{2} \sum_{j} \sum_{k} \beta_{j, k} \ln \hat{P}_{j} \ln \hat{P}_{k}+\beta_{\tau} \tau+\sum_{l=1}^{L-1} \gamma_{l} D F_{l}+v+u \\
& j, k \in\{L=\text { labour; } M=\text { materials }\} .
\end{aligned}
$$

$Y$, the output, is measured by the number of bus kilometers. Hence, as in most of the frontier analyses of the urban public transport sector, our output indicator is supply-orientated. The main argument explaining our choice is that demand-related measures (such as passenger-trips) are extremely dependent upon exogenous determinants such as the rates of unemployment and car ownership, which are unavailable at a disaggregated level in our database.

The input prices are defined as in Gagnepain and Ivaldi (2002a, 2002b) or Ottoz et al., (2009). $\hat{P}_{j}=P_{j} / P_{S}$ for $j=L, M$ are the normalized prices of the following inputs: labor $\left(P_{L}\right)$ and materials $\left(P_{M}\right)$, with respect to the price of overheads $\left(P_{S}\right){ }^{16}$ The average wage rate, $P_{L}$, is obtained by dividing total labor costs by the annual number of employees (full time equivalent). Materials include fuel, spares and repairs. ${ }^{17}$ The average price of materials, $P_{M}$, is obtained by dividing material expenditures by the number of vehicles, which mainly determines these expenditures. Expenditures in

${ }^{15}$ Gagnepain and Ivaldi (2002a), Piacenza (2006), Cambini et al. (2007).

${ }^{16}$ The monetary variables $V C, P_{L}$ and $P_{M}$ have been normalized with respect to the factor price $P_{S}$ to ensure that the cost function is homogenous of degree one in input prices.

${ }^{17}$ In our database, we cannot distinguish between the different categories of operating expenditures. In particular, it is not possible to isolate fuel expenditures from other categories of operational expenditures. 
spares in repairs are indeed directly linked to the number of vehicles; fuel expenditures are driven by the number of vehicles but also by their characteristics (mainly their age) and their use. To control for that, we include the average age of the bus fleet $(A G E)$ as a control variable. Likewise, traffic conditions and geographical characteristics are taken into account by incorporating the variables $S P$, which is the average commercial speed of buses (Piacenza, 2006) and $N$, the total length of the network. By doing so, we do not assume that all differences in operational expenditures are just due to price differences as we control for heterogeneity in the bus fleets and in the networks. Finally, overhead includes commercial vehicles, computer services, ticketing and office supplies and we derive an average price for this composite input, $P_{S}$, by dividing overhead expenditures by the number of customer trips per year.

At last, $\tau$ is a time trend variable and $D F_{l}$ are firm-specific dummies. $v$ is a noise error term and $u$ is the cost inefficiency term.

\subsection{Modeling Cost Inefficiency}

Cost inefficiencies are modeled as a truncated normal function $N\left(W_{i t} \delta, \sigma_{u}{ }^{2}\right)$ of several variables that are conjectured to explain differences in efficiency across city networks.

More precisely, we include, in the vector $W_{i t}$ of such explanatory variables, a dummy variable, PRIVATE, for networks operated by a private company, as opposed to networks operated by mixed companies, which correspond to the dummy MIXED. To capture the effect of incentive schemes we also incorporate in $W_{i t}$ the dummies CP, GROSS and NET for operators regulated by, respectively, cost-plus, gross cost and net cost contracts. We introduce the variable EXPIR defined as the number of remaining months before contract expiration. Finally, we include the combination of these different variables.

According to the incentive regulation literature, operators with different intrinsic ability/efficiency should be optimally regulated with different contracts: low-powered incentive contracts for less efficient firms and high-powered incentive contracts for more efficient ones (Laffont and Tirole, 1993). Hence, a better performance associated with a fixed-price contract would reflect higher effort but also higher intrinsic ability (a lower $c(0)$ in our model). As already mentioned, Gagnepain and Ivaldi (2002a) test this second effect and show that the empirical distributions of operators' efficiency parameters associated with fixed-price and cost-plus contracts are not significantly different. Following that, we can consider that contracts are exogenously given and that observed differences in efficiency levels for different organizational modes are explained by differences in effort levels and not by a difference in the intrinsic efficiency of the operators. 
Table 1: Sample Descriptive Statistics (111 Urban Networks and 8 Years)

\begin{tabular}{lcccc}
\hline \hline \multicolumn{1}{c}{ Variable } & Mean & Standard deviation & Minimum & Maximum \\
\hline Population & 105,468 & 76,014 & 24,588 & 370,000 \\
Size of the network $(\mathrm{km})$ & 164.39 & 129.68 & 17 & 645 \\
Age of the bus fleet $(\mathrm{years})$ & 8.2 & 1.9 & 3.3 & 16.5 \\
Commercial speed $(\mathrm{km} / \mathrm{h})$ & 16.43 & 2.52 & 11.4 & 30 \\
\hline \hline
\end{tabular}

\section{Data and Variables}

Our database assembles the results of two annual surveys conducted by an agency of the French Ministry of Transportation (CERTU) on the one hand and a trade organization that gathers most of the local authorities in charge of urban transport on the other hand (GART). The data is available for the period of 1995-2002 for a total of 165 networks (out of 241). But, for the sake of homogeneity, we have excluded the cities with at least one mass transit system (subway or tramway) which have, obviously, a different cost structure. Large French cities (Paris, Lyon, Toulouse...) are therefore not represented in our sample. For the same reason, we have also excluded the smallest cities (under 20000 inhabitants) ${ }^{18}$

Table 2: Descriptive Statistics on the Cost Structure

\begin{tabular}{lcccc}
\hline \multicolumn{1}{c}{ Variable } & Mean & Standard deviation & Minimum & Maximum \\
\hline VC: Variable cost $\left(10^{3} €\right)$ & 7628.73 & 8182.879 & 403.52 & 45111 \\
Y: Vehicle-km & 2683551.74 & 2598427.06 & 206000 & 11380524 \\
$P_{\mathrm{L}}$ : Price of labor $\left(10^{3} € /\right.$ worker) & 30.408 & 4.991 & 16.933 & 54.018 \\
$\mathrm{P}_{\mathrm{M}}$ : Price of materials $\left(10^{3} € /\right.$ vehicle) & 15.881 & 4.959 & 0.721 & 34.467 \\
$\mathrm{P}_{\mathrm{S}}$ : Price of overheads ( $€ /$ trip) & 0.266 & 0.221 & 0.006 & 1.775 \\
K: Capital (\# vehicles) & 68.870 & 63.268 & 6 & 365 \\
Labor cost-share & 0.631 & 0.106 & 0.268 & 0.946 \\
Materials cost-share & 0.160 & 0.044 & 0.008 & 0.451 \\
Overheads cost-share & 0.208 & 0.109 & 0.006 & 0.607 \\
\hline \hline
\end{tabular}

In addition, as our propositions only deal with the performance differential of various delegation contracts, we have excluded from the original sample all the cities where service is provided by a public administration (17 networks out of 165). The result is an unbalanced panel of 664 yearly observations covering 111 different urban transport networks over eight recent years (from 1995 to 2002 inclusively).

We present the sample descriptive statistics in three tables. Table 1 focuses on the characteristics of the networks and the cities of our sample, Table 2 on the data used to construct the cost function. In our sample, the average input prices are 30.4 thousands per worker per year, 15.8 thousands per operating expenses (including fuel) per bus per year ${ }^{19}$ and 0.266 per trip

${ }_{18}$ As a consequence of these selections, the few networks operated by a company regulated by a concession contract were excluded.

${ }^{19}$ Focusing on a similar time period (1998-2002), Ottoz et al. (2009) found a comparable 
for overhead expenses. Finally, Table 3 describes the potential explanatory variables of cost inefficiency.

Table 3: Descriptive Statistics on the Contractual Variables

\begin{tabular}{lcccc}
\hline \multicolumn{1}{c}{ Variable } & Mean & Standard deviation \\
\hline PRIVATE & $\mathbf{0 . 7 3}$ & & $\mathbf{0 . 4 4}$ & \\
PRIVATE* $C P$ & & 0.18 & & 0.38 \\
PRIVATE ${ }^{*}$ GROSS & & 0.17 & 0.38 \\
PRIVATE $N E T$ & & 0.38 & 0.44 & 0.49 \\
MIXED & $\mathbf{0 . 2 6}$ & & & 0.32 \\
MIXED*CP & & 0.11 & & 0.22 \\
MIXED*GROSS & & 0.06 & & 0.29 \\
MIXED*NET & & 0.09 & $\mathbf{3 0 . 2 8}$ & \\
EXPIR (months) & $\mathbf{5 0 . 7 6}$ & &
\end{tabular}

\section{Empirical Results}

Table 4 gives estimates of the cost frontier parameters while Table 5 presents the estimates of the inefficiency-related coefficients. Five models were estimated to test our propositions. The first one only considers in the inefficiency term the ownership regime of the operator, which is our proxy for the competitive intensity of the attribution procedure. The second and third ones consider, in addition to the ownership regime, the contractual type. Finally, in Models 4 and 5, we introduced the number of months before contract expiration to take into account for any dynamic effects of each type of contract.

\subsection{Technical Characteristics}

Since all the variables except the time trend and the firm specific dummies were normalized to their sample mean value, the estimated first order coefficients reported in Table 4 can be interpreted directly as frontier cost elasticities.

Consistently with other studies (De Borger et al. 2002 and Cambini et al. 2007 for reviews of the empirical literature), we find a significant and positive impact of an increase in output on cost. More precisely, the values exhibited by $\beta_{Y}$ indicate that a $10 \%$ increase of the bus-kilometers generates an increase of variable costs of the order of $5.3-7.1 \%$. Not surprisingly either, the estimated frontier cost elasticities with respect to the average commercial speed of the network $\left(\beta_{S P}\right)$ appears to be negative. As found for instance by Piacenza (2006), an increase in the commercial speed of urban transport buses by $10 \%$ induces a reduction in the level of operating costs by approximately 3\% (economies of higher speed).

price for expenditures in Italy of 17.4 thousand euros. 
Table 4: Maximum-Likelihood Estimates for Parameters of the Stochastic Frontier Cost Function

\begin{tabular}{|c|c|c|c|c|c|c|c|c|c|c|}
\hline \multirow[t]{2}{*}{ Coefficient $^{\mathrm{a}}$} & \multicolumn{2}{|c|}{ Model 1} & \multicolumn{2}{|c|}{ Model 2} & \multicolumn{2}{|c|}{ Model 3} & \multicolumn{2}{|c|}{ Model 4} & \multicolumn{2}{|c|}{ Model 5} \\
\hline & Estimates & Std & Estimates & Std & Estimates & Std & Estimates & Std & Estimates & Std \\
\hline$\beta_{0}$ & $-0.170 * * *$ & 0.017 & $-0.145^{* * *}$ & 0.027 & $-0.161^{* * *}$ & 0.031 & $-0.126 * * *$ & 0.022 & $-0.163 * * *$ & 0.031 \\
\hline$\beta_{\gamma}$ & $0.629 * * *$ & 0.047 & $0.713^{* * *}$ & 0.102 & $0.586 * * *$ & 0.079 & $0.530^{* * *}$ & 0.068 & $0.586^{* * *}$ & 0.059 \\
\hline$\beta_{N}$ & $-0.082^{* * *}$ & 0.017 & $-0.083^{* * *}$ & 0.018 & $-0.102 * * *$ & 0.018 & $-0.066 * * *$ & 0.024 & $-0.121 * * *$ & 0.021 \\
\hline$\beta_{\mathrm{SP}}$ & $-0.286 * * *$ & 0.049 & $-0.330 * * *$ & 0.069 & $-0.303^{* * *}$ & 0.066 & $-0.313 * * *$ & 0.072 & $-0.254^{* \cdots *}$ & 0.073 \\
\hline$\beta_{\text {AGE }}$ & -0.011 & 0.031 & $-0.082^{* *}$ & 0.042 & $-0.057^{* *}$ & 0.032 & -0.025 & 0.045 & -0.009 & 0.047 \\
\hline$\beta_{\mathrm{k}}$ & $0.476^{* * *}$ & 0.050 & $0.360^{* * *}$ & 0.106 & $0.505^{* * * *}$ & 0.082 & $0.548 * \cdots$ & 0.072 & $0.530 * * *$ & 0.064 \\
\hline$\beta_{L}$ & $0.632^{* * *}$ & 0.027 & $0.621^{* * *}$ & 0.045 & $0.581^{* * *}$ & 0.036 & $0.531^{* * *}$ & 0.039 & $0.618^{* * *}$ & 0.035 \\
\hline$\beta_{M}$ & $0.266^{* \cdots *}$ & 0.026 & $0.273^{* \cdots *}$ & 0.041 & $0.305^{* * *}$ & 0.032 & $0.362^{* * *}$ & 0.037 & $0.277^{* * *}$ & 0.034 \\
\hline$\beta_{Y, N}$ & $-0.346 * * *$ & 0.077 & $-0.264^{* * *}$ & 0.106 & $-0.434^{* *}$ & 0.108 & $-0.280^{* * *}$ & 0.108 & $-0.517^{\circ}$ & 0.345 \\
\hline$\beta_{\gamma, S P}$ & 0.197 & 0.204 & 0.433 & 0.549 & 0.820 & 0.642 & -0.028 & 0.282 & $0.951^{* * *}$ & 0.365 \\
\hline$\beta_{Y, A G E}$ & $0.185^{*}$ & 0.137 & 0.377 & 0.456 & 0.253 & 0.411 & $0.310^{*}$ & 0.197 & 0.333 & 0.380 \\
\hline$\beta_{Y, K}$ & $-0.567^{* * *}$ & 0.248 & -0.534 & 0.568 & -0.637 & 0.564 & $-0.689^{* *}$ & 0.383 & -0.671 & 0.536 \\
\hline$\beta_{Y, L}$ & $0.203^{* *}$ & 0.103 & 0.201 & 0.367 & 0.282 & 0.369 & 0.132 & 0.149 & 0.247 & 0.311 \\
\hline$\beta_{\mathrm{r}, \mathrm{M}}$ & $-0.196^{* *}$ & 0.104 & -0.117 & 0.364 & -0.307 & 0.387 & -0.135 & 0.150 & -0.304 & 0.322 \\
\hline$\beta_{\mathrm{N} S P}$ & $0.277^{* * *}$ & 0.102 & 0.23 & 0.159 & 0.152 & 0.171 & $0.353^{* * *}$ & 0.148 & 0.2 & 0.159 \\
\hline$\beta_{\text {NAGE }}$ & -0.037 & 0.067 & -0.015 & 0.106 & -0.005 & 0.068 & -0.003 & 0.094 & & 0.138 \\
\hline$\beta_{\mathrm{NK}}$ & $0.384^{* * *}$ & 0.092 & $0.230^{* * *}$ & 0.120 & $0.493^{* * *}$ & 0.146 & $0.306^{* * *}$ & 0.128 & $0.593^{*}$ & 0.409 \\
\hline$\beta_{\mathrm{N}, \mathrm{L}}$ & $-0.083 * * *$ & 0.039 & -0.048 & 0.051 & $-0.089^{\circ}$ & 0.048 & $-0.072^{*}$ & 0.055 & $-0.174 * * *$ & 0.052 \\
\hline$\beta_{N, M}$ & -0.013 & 0.036 & -0.038 & 0.425 & -0.033 & 0.043 & -0.032 & 0.050 & $0.061^{*}$ & 0.039 \\
\hline$\beta_{S P, A G E}$ & -0.2 & 0.168 & 0.110 & & & & & 0.238 & & 0.758 \\
\hline$\beta_{S P, k}$ & $-0.586^{* * * *}$ & 0.221 & -0.785 & 0.617 & $-1.137^{\bullet *}$ & 0.645 & $-0.407^{*}$ & 0.307 & $-1.368^{* *}$ & 0.336 \\
\hline$\beta_{S P, L}$ & $0.397^{* * *}$ & 0.099 & $0.418^{* * *}$ & 0.170 & $0.477^{* * * *}$ & 0.145 & $0.242^{* *}$ & 0.138 & 0.567 & 0.485 \\
\hline$\beta_{S P, M}$ & $-0.349 * * *$ & 0.100 & $-0.416^{* * *}$ & 0.174 & $-0.468 * \cdots *$ & 0.153 & -0.135 & 0.138 & -0.502 & 0.508 \\
\hline$\beta_{A G E, K}$ & -0.147 & 0.151 & -0.343 & 0.509 & -0.238 & 0.442 & $-0.328^{*}$ & 0.216 & -0.236 & 0.414 \\
\hline$\beta_{A G E, L}$ & $0.107^{*}$ & 0.067 & 0.146 & & 0.147 & & & & & 0.087 \\
\hline$\beta_{A G E, M}$ & $-0.098^{*}$ & 0.068 & -0.116 & 0.141 & & & & 0.094 & & 0.091 \\
\hline$\beta_{k, L}$ & $-0.155^{*}$ & 0.111 & -0.172 & & & & & & & 0.337 \\
\hline$\beta_{\mathrm{KMM}}$ & $0.229 * \cdots$ & 0.111 & 0.150 & 0.411 & 0.373 & 0.423 & $0.266^{* *}$ & 0.160 & 0.296 & 0.352 \\
\hline$\beta_{Y, Y}$ & $0.689^{* * *}$ & 0.243 & 0.592 & 0.545 & $0.790^{*}$ & 0.537 & $0.669^{* *}$ & 0.375 & $0.863^{*}$ & 0.581 \\
\hline$\beta_{N, N}$ & 0.012 & 0.040 & 0.069 & 0.054 & -0.019 & 0.059 & 0.041 & 0.058 & -0.018 & 0.071 \\
\hline$\beta_{S P, S P}$ & 0.023 & 0.306 & 0.125 & 0.867 & 0.272 & 0.794 & 0.320 & 0.429 & 0.247 & 0.966 \\
\hline$\beta_{A G E, A G E}$ & -0.166 & 0.139 & 0.200 & 0.328 & 0.008 & 0.252 & 0.003 & 0.196 & -0.145 & 0.429 \\
\hline$\beta_{k x}$ & $0.457^{*}$ & 0.277 & 0.508 & 0.616 & 0.439 & 0.615 & $0.704^{*}$ & 0.425 & 0.462 & 0.671 \\
\hline$\beta_{L, M}$ & $-0.210^{* * *}$ & 0.022 & $-0.220 * * *$ & 0.027 & $-0.236 * * *$ & 0.025 & $-0.218 * * *$ & 0.030 & $-0.204 * * *$ & 0.057 \\
\hline$\beta_{L, L}$ & $0.236^{* \cdots *}$ & 0.031 & $0.235^{* \cdots *}$ & 0.042 & $0.250^{* * *}$ & 0.037 & $0.226^{* * *}$ & 0.042 & $0.223^{* * *}$ & 0.082 \\
\hline$\beta_{M, M}$ & $0.222^{* * *}$ & 0.027 & $0.215^{* * *}$ & 0.027 & $0.230^{* * * *}$ & 0.027 & $0.228^{* * *}$ & 0.039 & $0.208^{* * *}$ & 0.035 \\
\hline$\beta_{t}$ & $0.005^{* * *}$ & 0.002 & 0.004 & 0.003 & 0.002 & 0.003 & $0.009 * \cdots$ & 0.003 & $0.006^{* *}$ & 0.003 \\
\hline Obs. & 664 & & 664 & & 664 & & 664 & & 664 & \\
\hline
\end{tabular}

${ }^{a}$ Dependent variable: VC; estimates of firm-specific fixed effects not reported. ${ }^{* * *}$ Significant at the $1 \%$ level, ${ }^{* *}$ significant at the $5 \%$ level, ${ }^{*}$ significant at the $10 \%$ level. 
An increase in the network size is found to impact negatively on costs as $\beta_{N}$ is negative in all the estimates. This means that for given inputs and outputs, a longer network reduces the cost. This result suggests that the merger between neighboring cities to extend networks may be a good option (Cambini et al. 2007). The age of the bus fleet does not appear to impact significantly on costs but this may be due to the low variance of the variable AGE.

All the estimates reported in Table 4 also show that the fixed input parameter, $\beta_{K}$, has a positive sign, suggesting that the variable costs increase with larger rolling stock. Although counterintuitive, this result is consistent with the vast majority of empirical studies dealing with the cost efficiency of urban public transport networks (Piacenza, 2006; Cambini et al. 2007) and may reflect an inefficient use of capital.

Table 5: Maximum-Likelihood Estimates for Parameters of the Stochastic Inefficiency Model

\begin{tabular}{|c|c|c|c|c|c|}
\hline Coefficient & Model 1 & Model 2 & Model 3 & Model 4 & Model 5 \\
\hline$\delta_{0}$ & $\begin{array}{c}-0.951^{* * *} \\
(0.086)\end{array}$ & $\begin{array}{c}-0.058 \\
(0.047)\end{array}$ & $\begin{array}{c}-0.154^{* * *} \\
(0.074)\end{array}$ & $\begin{array}{c}-0.011 \\
(-0.099)\end{array}$ & $\begin{array}{c}-0.094^{*} \\
(0.067)\end{array}$ \\
\hline$\delta_{\text {PRIVATE }}$ & $\begin{array}{c}-1.298 * * * \\
(0.126)\end{array}$ & - & - & - & - \\
\hline$\delta_{\text {PRIVATE*CP }}$ & - & $\begin{array}{c}-1.059 \cdots \\
(0.235)\end{array}$ & $\begin{array}{c}-0.679^{* *} \\
(0.348)\end{array}$ & $\begin{array}{c}-0.896 * * * \\
(0.326)\end{array}$ & $\begin{array}{l}-1.255 \\
(1.042)\end{array}$ \\
\hline$\delta_{\text {PRIVATE*GROSS }}$ & - & $\begin{array}{c}-1.303^{\cdots *} \\
(0.398)\end{array}$ & $\begin{array}{c}-1.164^{* * *} \\
(0.512)\end{array}$ & $\begin{array}{c}-1.352^{* * *} \\
(0.388)\end{array}$ & $\begin{array}{c}-1.382^{* * *} \\
(0.218)\end{array}$ \\
\hline$\delta_{\text {PRIVATE*NET }}$ & - & $\begin{array}{c}-0.132^{\circ} \\
(0.077)\end{array}$ & $\begin{array}{c}-0.027 \\
(0.119)\end{array}$ & $\begin{array}{l}-0.156 \\
(0.161)\end{array}$ & $\begin{array}{c}-0.556^{* * * *} \\
(0.242)\end{array}$ \\
\hline$\delta_{\text {MIXED*CP }}$ & - & - & $\begin{array}{c}0.145^{* *} \\
(0.076)\end{array}$ & - & $\begin{array}{c}0.185 \\
(0.177)\end{array}$ \\
\hline$\delta_{\text {MIXED*GROSS }}$ & - & - & - & $\begin{array}{l}-0.242 \\
(0.181)\end{array}$ & - \\
\hline$\delta_{\text {MIXED*NET }}$ & - & - & - & $\begin{array}{l}-0.130 \\
(0.124)\end{array}$ & - \\
\hline$\delta_{\text {EXPIR }}$ PRIVATE & - & - & - & - & - \\
\hline$\delta_{\text {EXPIR*PRIVATE*CP }}$ & - & - & - & - & $\begin{array}{c}0.003 \\
(0.014)\end{array}$ \\
\hline 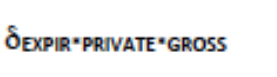 & - & - & - & - & $\begin{array}{c}0.014^{* * *} \\
(0.003)\end{array}$ \\
\hline$\delta_{\text {EXPIR*PRIVATE*NET }}$ & - & - & - & - & $\begin{array}{c}0.005^{* *} \\
(0.003)\end{array}$ \\
\hline$\delta_{\text {EXPIR*MIXED*CP }}$ & - & - & - & - & $\begin{array}{c}-0.006^{*} \\
(0.004)\end{array}$ \\
\hline$\sigma^{2}$ & $\begin{array}{c}0.088^{* * * *} \\
(0.004)\end{array}$ & $\begin{array}{c}0.039 * \cdots \\
(0.004)^{* *}\end{array}$ & $\begin{array}{c}0.036 * * * \\
(0.004)\end{array}$ & $\begin{array}{c}0.038^{* * *} \\
(0.003)\end{array}$ & $\begin{array}{c}0.033^{* * *} \\
(0.007)\end{array}$ \\
\hline$\gamma$ & $\begin{array}{c}0.878 * * * \\
(0.014)\end{array}$ & $\begin{array}{c}0.704 * * \\
(0.059)\end{array}$ & $\begin{array}{c}0.711^{* * *} \\
(0.075)\end{array}$ & $\begin{array}{c}0.717^{* * * *} \\
(0.053)\end{array}$ & $\begin{array}{c}0.771 * * * \\
(0.046)\end{array}$ \\
\hline System Log-likelihood & 576.776 & 523.412 & 516.807 & 523.447 & 512.939 \\
\hline
\end{tabular}

*** Significant at the $1 \%$ level, ${ }^{* *}$ significant at the $5 \%$ level, * significant at the $10 \%$ level. Standard errors in brackets.

At last, the results reveal the presence of both density (RTD) and scale (RTS) economies, which coincides with the results of pervious studies on the technology of public transport systems. Indeed, as shown in Table 6, 
short-run returns to scale vary between 1.587 and 2.155 , depending on the model, while short-run returns to density range from 1.402 to 1.867 .

Table 6: Estimates of Short-Run Economies of Scale (SRTS) and Economies of Network Density (SRTD) for the Various Models

\begin{tabular}{cccccc}
\hline \hline & Model 1 & Model 2 & Model 3 & Model 4 & Model 5 \\
\hline $\operatorname{SRTS}\left(\frac{1}{\varepsilon_{Y}+\varepsilon_{N}}\right)$ & 1.828 & 1.587 & 2.066 & 2.155 & 2.150 \\
\hline $\operatorname{SRTD}\left(\frac{1}{\varepsilon_{Y}}\right)$ & 1.589 & 1.402 & 1.706 & 1.867 & 1.706 \\
\hline \hline
\end{tabular}

\subsection{Cost Inefficiency and Effects of Incentive Schemes and Con- tract Renewal}

Our theoretical propositions show that the optimal effort path depends on both the contractual type and the competitive intensity of the attribution process. We now confront these propositions with the results of our econometric model. To do that, we interpret the parameters of the stochastic inefficiency model, presented in Table 5, and the inefficiency scores, presented in Tables 7 and 8. Our idea is that by exerting a cost-minimizing effort, public transport operators manage to reduce their cost, i.e. move closer to the cost frontier. In other words, by exerting effort, firms reduce their cost inefficiency.

The estimates of the inefficiency-related coefficients, $\delta$, and the two variance parameters, $\gamma$ and $\sigma^{2}$, are presented in Table 5. In all models, the parameter $\gamma$ is statistically different from zero, which indicates that the stochastic cost frontier is an appropriate approach. Moreover, the specification tests to which we proceeded (see Table 9 in Appendix B) allow rejecting the CobbDouglas frontier at a reasonable level of significance. The hypothesis that $\gamma$ and the parameters of the inefficiency functions are jointly equal to zero is also rejected as is the hypothesis of the absence of impact of regulatory schemes and time to expiration. This indicates that the inefficiency effects in the frontier are clearly stochastic.

Looking at the results of Model 1, it appears that private operators are less inefficient than mixed ones (the omitted case) as $\delta_{P R I V A T E}$ is significantly different from zero and negative. This result is consistent with our proposition 4, which states that private operators should be closer to the cost frontier than mixed ones because the former face more competition at the contract attribution stage.

The incentive schemes also appear to have a significant impact on the cost efficiency of private urban bus operators. Results of Model 2 indeed suggest that private operators regulated by gross cost contracts are the least inefficient since $\delta_{P R I V A T E * G R O S S}$ is significant at the $1 \%$ level, negative and 
significantly inferior to $\delta_{P R I V A T E * C P}$ and $\delta_{P R I V A T E * N E T}$. This result supports our propositions 3 and $5 \mathrm{a}$, which conjectured that gross cost contracts provide the greatest incentives for cost minimization.

Several empirical studies have already shown that fixed-price contracts provide more incentives for cost efficiency than cost-plus contracts (Bajari and Tadelis, 2001; Gagnepain and Ivaldi, 2002a; Aubert and Reynaud, 2005; Piacenza, 2006). The fact that, in our results, operators under gross cost contracts, which are a type of fixed-price contracts, appear as more efficient than operators under cost-plus contracts is then a classical result. However, what is more original in our approach is that we distinguish between two types of fixed-price contracts, namely gross cost and net cost contracts. Such a distinction proves to be of interest as results of our estimates (Model 2) indicate that gross cost and net cost contracts are not equivalent in terms of cost efficiency. Indeed, regulation by gross cost contracts appears to provide more incentives for cost minimization than the net cost contract as the estimated coefficient $\left|\delta_{P R I V A T E * N E T}\right|$ is significantly inferior (in absolute value) to $\left|\delta_{P R I V A T E * G R O S S}\right|$. This result is consistent with our proposition 5: with net cost contracts, operators focus more on commercial parameters (traffic volume, receipts, service quality) than on cost parameters due to scarce managerial resources ${ }^{20}$ Hence, with net cost contracts, cost-minimizing effort is crowded out by other effort dimensions such as commercial effort.

In Model 3, where we further distinguish between mixed firms regulated by cost-plus and fixed-price (gross cost and net cost) contracts, the results confirm that private operators, whatever their contract, are more efficient than mixed firms $\left(\delta_{P R I V A T E * C P}, \delta_{P R I V A T E * G R O S S}\right.$ and $\delta_{P R I V A T E * N E T}$ are all negative). Moreover, as in Model 2, private operators under gross cost contracts are the closest to the cost frontier. What comes out in addition in Model 3 is that the variable $\delta_{M I X E D * C P}$ is positive and significantly different from zero. Thus, a mixed firm regulated by a cost-plus contract is the least efficient contractual and ownership mix. Model 4 further distinguishes the three contracts for the mixed firms. There is no significative difference between the two types of fixed price contracts and they are more efficient than the cost-plus one. To summarize this first set of results, we provide in Table 7 the mean inefficiency scores of urban bus operators by types of contracts and ownership regimes.

First, private operators, who face more competition at the contract renewal stage than mixed ones, exhibit a smaller mean inefficiency score (1.055 for private operators compared to 1.102 for mixed ones).

Second, the most efficient operators appear to be the private operators regulated by gross cost contracts. Their mean inefficiency is 1.019 , meaning that their actual costs are on average 1.9\% higher than the estimated best

${ }^{20} \mathrm{Or}$, to a conflict between cost-minimization and increasing traffic receipts. Indeed, some dimensions of service quality such as safety, cleanness of buses, maintenance, and tickets control are associated with higher spending. 
Table 7: Mean Inefficiency Scores of City Networks by Type of Contract and Operator

\begin{tabular}{llllll}
\hline \hline Operator's ownership & Type of contract & Mean & Standard deviation & Min & Max \\
\hline PRIVATE & CP & 1.028 & 0.006 & 1.000 & 1.049 \\
PRIVATE & GROSS & 1.019 & 0.004 & 1.000 & 1.028 \\
PRIVATE & NET & 1.085 & 0.034 & 1.028 & 1.212 \\
PRIVATE & & 1.055 & 0.040 & 1.000 & 1.212 \\
MIXED & CP & 1.128 & 0.051 & 1.049 & 1.344 \\
MIXED & GROSS+NET & 1.082 & 0.032 & 1.029 & 1.222 \\
MIXED & & 1.102 & 0.047 & 1.029 & 1.344 \\
TOTAL & & $\mathbf{1 . 0 6 8}$ & $\mathbf{0 . 0 4 7}$ & $\mathbf{1 . 0 0 0}$ & $\mathbf{1 . 3 4 4}$ \\
\hline \hline
\end{tabular}

Notes: Inefficiency scores derived from estimates of Model 4.

practices costs. Private operators regulated by cost-plus contracts and net cost contracts stand further from the cost frontier as their mean inefficiency is respectively 1.028 and 1.085 . Hence, consistently with our expectations, the regulatory framework under which private firms operate has a huge impact on variable costs. All things being equal, the cost of a private bus operator under a net cost contract is on average $5.7 \%$ higher than for operators under a cost plus contract, and $6.6 \%$ greater than for operators under a gross cost contract.

At last, the average inefficiency score for mixed operators is equal to 1.102 with firms regulated by a cost-plus having, in average, a higher inefficiency score (1.128) than those regulated by a fixed-price (1.082)

The second set of results regards the effort path. According to our propositions 1 and 2, effort is not constant during the contracting period and the effort path has a different shape for cost-plus and gross cost contracts. To empirically investigate whether effort varies during the contracting period, we incorporate in Models 5 the remaining duration of the contract (EX$P I R)$ and we estimate the impact on inefficiency. More precisely, we include three specific variables for private operators, one for each contract type: $E X$ PIR ${ }^{*}$ PRIVATE ${ }^{*} C P$, EXPIR ${ }^{*}$ PRIVATE*GROSS and EXPIR*PRIVATE*NET and one variable for mixed firms regulated by a cost-plus contract, EXPIR*MIX$E D^{*} C P$.

Results of our estimates indicate that private operators tend to have a higher cost at the beginning of the contract, since $\delta_{E X P I R * P R I V A T E * G R O S S}$, $\delta_{E X P I R * P R I V A T E * N E T}$ and $\delta_{E X P I R * P R I V A T E * C P}$ are positive. In other words, the longer the remaining duration of the contract (i.e. the higher EXPIR), the more inefficient the private operators. The incentives coming from the perspective of contract renewal that we identified call for a good performance at the end of the contacting period and we observe that private firms are continuously increasing their cost performance during the contract. Notice that this effect of time to expiration is significant only for gross (at the $5 \%$ level) and net (at the 1\% level) cost contracts. Better cost-performances closer the expiration date effectively confirm that the renewal decision depends on realized costs.

This must be contrasted with the coefficient $\delta_{E X P I R * M I X E D * C P}$ that is 
Table 8: Mean Inefficiency Scores of Privately Operated Networks and Time to Expiration

\begin{tabular}{|c|c|c|c|c|c|c|c|c|}
\hline \multicolumn{2}{|c|}{ Time to contract expiration (years) } & $\geq 7$ & ]7; 6] & ]6;5] & ]5; 4] & ]4; 3] & ]3;2] & ]2; 0[ \\
\hline \multirow{3}{*}{ 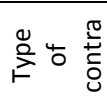 } & PRIVATE*CP & 1.020 & 1.023 & 1.021 & 1.021 & 1.019 & 1.020 & 1.018 \\
\hline & PRIVATE*GROSS & 1.068 & 1.037 & 1.032 & 1.026 & 1.022 & 1.019 & 1.019 \\
\hline & PRIVATE*NET & 1.096 & 1.057 & 1.055 & 1.047 & 1.048 & 1.049 & 1.040 \\
\hline
\end{tabular}

Notes: Inefficiency scores derived from estimates of Model 5.

negative and significant (at the 10\% level) showing that performances of mixed companies regulated by a cost-plus contract deteriorate during the contracting period. These operators are not responsible for the productive and commercial risks and, furthermore, due to the lack of competitiveness of the contract renewal process, the threat of termination is limited. Accordingly, we observe that these operators have no incentives to improve performance and, contrarily, we observe that performances deteriorate during the contract.

An interesting way to analyze the shape of the effort path is to look at the evolution of the mean inefficiency scores during the life of the contract. These inefficiency scores are presented in Table 8. It reveals that the average efficiency score of private operators regulated by cost-plus contracts remains pretty stable during the contracting period. Such operators indeed have an average inefficiency score of 1.020 when the time to contract expiration is superior or equal to 7 years, while their mean inefficiency is only 1.018 when there are less than 2 years before the end of the contract. What is of particular interest is that operators regulated by a gross cost or net cost exhibit a huge decrease in their inefficiency score at the beginning of a new contract. In other words, such operators significantly improve their performance during the life-time of the contract, and especially at the beginning of the contract. With a net cost contract, the inefficiency decreases by $5.6 \%$ during the contract and more than half of the efficiency gain is already capitalized at the beginning of the contract. Similarly, for a gross cost contract, the inefficiency decreases by $4.9 \%$ with a $3.1 \%$ efficiency gains at the beginning.

With a net cost contract, private operators tend to be less efficient, in average, than with the other regulatory schemes, but this contractual form leads to the largest performance improvement during the contracting period. Interestingly, changes in efficiency could be interpreted as cost-reducing effort which are taking place mainly at the beginning of the contract. As we have shown, efforts that produce long-lasting effects on costs should be undertaken as early as possible when efforts have an impact on the firm's profit.

To summarize, our theoretical model sheds light on (1) the importance of contract renewal as an incentive device (propositions 1, 2 and 4), (2) the differences between the three contract types (propositions 3 and 5) and (3) the allocation of effort during the contracting period (propositions 1 and 2). 
In our empirical analysis, we found support for at least part our theoretical results.

Even if competition for contract is limited in the French urban transport industry, the perspective of contract renewal appears to be an important incentive device. Indeed, private firms, including those regulated by a lowpowered incentive scheme, are found to be more efficient than mixed ones for which competition for contracts is extremely limited not to say inexistent. This indicates that more competitive tenders provide incentives to exert-cost reducing effort, even if the current profit flow is not affected as for the cost-plus contract. We thus have empirical support for proposition 4.

We also observe substantial differences between contract types. To promote cost-efficiency, the gross cost contract seems to be the most appropriate instrument as stated in propositions 3 and 5. With the gross and the net cost contract, the firm bears the responsibility for the productive risk. Despite that, cost inefficiencies are lower with the gross cost contract. We explain this result by a crowding-out effect. With a net cost contract, the cost-minimizing effort is either more costly to perform due to scarce managerial resources or, eventually, in conflict with other objectives such as promoting the use of public transport.

Finally, our model shows that, when delegation and effective competition are combined with a high-powered incentive contract, the firm has incentives to implement cost-minimizing measures at the beginning of the relation. Indeed, an effort that has a long-lasting effect brings higher benefits when it is undertaken earlier. Our proposition 2 received empirical support as we observed that cost inefficiency decreases sharply at the beginning of the relation if the contract is a gross cost or a net cost. With a cost-plus contract, effort is more equally spread during the relation because the perspective of contract renewal calls for a good performance at the end of the contract. We thus have mixed evidences regarding our first proposition.

\section{Concluding Remarks}

In this paper, we have shown that both the optimal level of cost-reducing effort and its repartition during the contracting period are affected by the contract type combined with the specific incentives generated by contract renewal. To conclude the paper, we present suggestions for policy reform.

Outsourcing service provision to the private sector is often advocated as a measure to improve the efficiency of public transport. However, as stressed in this paper, delegation in itself is not enough and must be combined with effective competition for the field. Promoting competition, in the short and in the long run, is thus a key element of any public transport reform. 
In France, competition remains limited in the urban public transport sector and this can be partially explained by the high level of concentration of the market. Nevertheless, there are regulatory reforms that can be implemented to improve the competitiveness of the contract attribution process. Hereafter, we detail a few.

First, in the current procedure, contracts are not necessarily attributed to the lowest or even to the best bid. Local governments have the choice of the contractor as long as they are able to justify their choice. Such a negotiation procedure might well be appropriate when the service to be provided is complex, but there is no reason to adopt the same procedures for all types of contracts (Bajari and Tadelis, 2001). As a matter of fact, Bajari and Tadelis (2001) recommend the use of either a negotiation combined with a cost-plus contract or an auction combined with a fixed-price contract. An explicit auction, eventually with pre-qualified bidders, may stimulate competition when the contract is a gross or a net cost contract. And, if there is a fear that bidders would submit low bids by degrading the service quality, the contract could contain explicit incentives for the provision of a quality ${ }^{21}$ or leave the commercial receipts to the operator.

Second, tendering procedure participation must be stimulated. As mentioned above, the attribution procedure lacks transparency and this may deter participation. Making the procedure more transparent may stimulate competition, improve the performances of the contractor and lower the subsidies. Likewise, even if we identify economies of scale and density in the urban public transport sector, large-scale contracts may act as a barrier to entry for small size firms. Divisions into lots may increase the competition for contracts and this must be traded-off against the decline in productive efficiency.

Third, the hybrid organization that constitutes the mixed firm is undoubtedly associated with lower performances. We believe that these weak performances are at least partially explained by the fact that this type of firm is sheltered from competition. Indeed, local governments are, in this case, involved both in the management and in the contract attribution process. Clearly enough, this may deter potential competitors. To promote effective competition for contracts, local governments should abandon this hybrid organizational form and opt either for in-house production or full delegation to private operators.

Promoting effective competition is not the only tool that local governments can use to increase the performance of their local public transport firm. The choice of an appropriate contract to monitor the relation is also sensitive. Each contract has its own merits. The gross cost contract is the contractual form that provides the strongest incentives for cost minimization but it focuses exclusively on cost and other dimensions might be neglected. Cost-plus contracts, combined with effective competition, do fairly

\footnotetext{
${ }^{21}$ As it is done in London (Amaral et al. 2009).
} 
well on the cost side. Moreover, the cost-plus contract is a flexible contractual form that better accommodates ex-post adaptations (Bajari and Tadelis, 2001). The cost inefficiency of firms regulated by a net cost contract is higher but we conjecture that this lower cost performance is countervailed by better performances in other areas (traffic receipts, quality...).

The relative merits of each contract differ and local government should choose the contract that best suits their needs. Probably due to a lack of expertise, contractual choices are not fully explained by network characteristics (Gagnepain and Ivaldi, 2002a; Caillaud and Quinet, 1993). Thus, there is room for improving performances by making better contractual choices, more in line with the needs of local governments. 


\section{References}

Amaral, M., Saussier, S., Yvrande-Billon, A., 2009. Auction Procedures and Competition in Public Service: The Case of Urban Public Transport in France and London. Utilities Policy 17, 166-175. doi:10.1016/j.jup.2008.07.006

Amaral, M., Yvrande-Billon, A., 2009. Make or Buy Urban Public Transport Services: A Rational Choice? Working Paper EPPP N²009-03.

Aubert, C., Reynaud, A., 2005. The Impact of Regulation on Cost Efficiency: An Empirical Analysis of Wisconsin Water Utilities. Journal of Productivity Analysis 23, 383-409. doi:10.1007/s11123-005-2216-8

Bajari, P., Tadelis, S., 2001. Incentives versus Transaction Costs: A Theory of Procurement Contracts. RAND Journal of Economics 32, 387-407. doi:10.2307/2696361

Battese, G.E., Coelli, T.J., 1995. A Model for Technical Inefficiency Effects in a Stochastic Frontier Production Function for Panel Data. Empirical Economics 20, 325-332. doi:10.1007/BF01205442

Caillaud, B., Quinet, E., 1993. Analyse du Caractère Incitatif des Contrats de Transport Urbain. CEPREMAP Working Paper 9307.

Cambini, C., Piacenza, M., Vannoni, D., 2007. Restructuring Public Transit Systems: Evidence on Cost Properties from Medium and Large-Sized Companies. Review of Industrial Organization 31, 183-203. doi:10.1007/s11151-007-9153-9

Coelli, T., Estache, A., Perelman, S., Trujillo, L., 2003. A Primer on Efficiency Measurement for Utilities and Transport Regulators. Washington: The World Bank Institute.

Coelli, T., Rao, D.S.P., Battese, G.E., 1998. An Introduction to Efficiency and Productivity Analysis. Boston: Kluwer Academic Publishers. doi:10.1007/978-1-4615-5493-6

Conseil de la Concurrence, 2005. Décision N05-D-38 du 5 juillet 2005 relative à des pratiques mises en œuvre sur le marché du transport public urbain de voyageurs, Paris.

Dalen, D.M., Moen, E.R., Riis, C., 2006. Contract Renewal and Incentives in Public Procurement. International Journal of Industrial Organization 24, 269-285. doi:10.1016/j.ijindorg.2005.04.004 
Dalen, D.M., Gomez-Lobo, A., 2003. Yardsticks on the Road: Regulatory Contracts and Cost Efficiency in the Norwegian Bus Industry. Transportation 30, 371-386. doi:10.1023/A:1024784517628

De Borger, B., Kerstens, K., Costa, A., 2002. Public Transit Performance: What does one Learn from Frontier Studies? Transport Reviews 22, 1-38. doi:10.1080/01441640010020313

Desrieux, C., Chong, E., Saussier, S., 2010. Putting All One's Eggs in One Basket: Relational Contracts and the Provision of Local Public Services. Working Paper EPPP N²010-06.

Gagnepain, P., Ivaldi, M., 2002a. Incentive Regulatory Policies: The Case of Public Transit Systems in France. RAND Journal of Economics 33, 605-629. doi:10.2307/3087477

Gagnepain, P., Ivaldi, M., 2002b. Stochastic Frontiers and Asymmetric Information Models. Journal of Productivity Analysis 18, 145-199. doi:10.1023/A:1016582220790

GART 2005. La Passation des DSP en Transport Urbain. GART, Paris.

GART 2009. L'Année 2008 des Transports Urbains. GART, Paris.

Iossa, E., Rey, P., 2009. Building Reputation for Contract Renewal: Implications for Performance Dynamics and Contract Duration. CEIS Research paper 155.

Kodde, D.A., Palm, F.C., 1986. Wald Criteria for Jointly Testing Equality and Inequality Constraints. Econometrica 54, 1243-1248. doi:10.2307/1912331

Kumbkakar, S.C., Knox Lovell, C.A., 2000. Stochastic Frontier Analysis. Cambridge University Press. doi:10.1017/CBO9781139174411

Laffont, J.-J., Tirole, J., 1993. A Theory of Incentives in Procurement and Regulation. Cambridge: MIT Press.

Margari B., Erbetta, F., Petraglia, C., Piacenza, M., 2007. Regulatory and Environmental Effects on Public Transit Efficiency: A Mixed DEA-SFA Approach. Journal of Regulatory Economics 32, 131-151. doi:10.1007/s11149007-9025-0

Murillo-Zamarano, L.R., 2004. Economic Efficiency and Frontier Techniques. Journal of Economic Survey 18, 33-77. doi:10.1111/j.14676419.2004.00215.x

Ottoz, E., Fornengo, G., Di Giacomo, M., 2009. The Impact of Ownership on the Cost of Bus Service Provision: an Example from Italy. Applied Economics 41, 337-349. doi:10.1080/00036840601007260 
Piacenza, M., 2006. Regulatory Contracts and Cost Efficiency: Stochastic Frontier Evidence from the Italian Local Public Transport. Journal of Productivity Analysis 25, 257-277. doi:10.1007/s11123-006-7643-7

Roy, W., Yvrande-Billon, A., 2007. Ownership, Contractual Practices and Technical Efficiency: The Case of Urban Public Transport in France. Journal of Transport Economics and Policy 41, 257-282.

UTP, 2009. Les principaux chiffres 2008. UTP, Paris.

Yvrande-Billon, A., 2006. The Attribution Process of Delegation Contracts in the French Urban Public Transport Sector: Why Competitive Tendering is a Myth. Annals of Public and Cooperative Economics 77, 453-478. doi:10.1111/j.1467-8292.2006.00315.x 


\section{Appendix A: Complement to Section 3.2 and Proof of Proposition 5}

The operator could exert two types of effort: (i) cost-reducing effort $a_{1}(t)$, with $\dot{c}=-a_{1}(t)$ and/or (ii) commercial effort $a_{2}(t)$, with $\dot{x}=f\left(a_{2}(t)\right)$ and $f^{\prime}>0$. The cost of effort is $\psi\left(a_{1}(t), a_{2}(t)\right)$. This function is increasing and convex in its two arguments and the two efforts are partially substitutes: $\frac{\partial^{2} \psi}{\partial a_{1}(t) \partial a_{2}(t)} \geq 0$.

In a competitive bidding for a fixed-price contract, assume that the contract is awarded to the firm who ask for the lowest amount of subsidy. In the case of a gross cost contract, the lowest bidder is likely to be the firm with the lowest cost and the renewal probability satisfies $d P / d c(T)=P^{\prime}<0$. In the case of a net cost contract, the lowest bidder is likely to be the firm that could achieve the lowest operating deficit $(=c(T)-\bar{p} x(T) \geq 0)$. And, since a cost reduction of 1 euro has the same impact on the operating losses than an increase of 1 euro in the commercial receipts, the probability of contract renewal could be expressed as $P[c(T)-\bar{p} x(T)]$ with $P_{c}=d P / d c(T)=$ $-\bar{p} P_{x}=-d P / d x(T)<0$. Suppose that the impact of a given cost reduction on the renewal probability is the same for both contract types. That is $P^{\prime}$ is identical for the two contracts: $P^{\prime}=P_{c}$. We have:

1. The contract is a gross cost contract. The profit of the firm is $\bar{\pi}(t)=$ $p^{G C}-\bar{c}(t)-\psi\left(a_{1}(t), a_{2}(t)\right)$ and the firm's objective writes as follow $\max _{a_{1}(t), a_{2}(t)} \int_{0}^{T} e^{-\rho t} \bar{\pi}(t) d t+P(\bar{c}(T)) \bar{\pi}$ subject to $\dot{c}=-a_{1}(t), c(0)$ and $\mathrm{T}$ given. The solution to this problem is $a_{2}^{G C}(t)=0$ and $a_{1}^{G C}(t)$ is given by proposition 2 .

2. The contract is a net cost contract. The profit of the firm is $\bar{\pi}(t)=$ $p^{N C}+\bar{p} x(t)-\bar{c}(t)-\psi\left(a_{1}(t), a_{2}(t)\right)$ and the firm's objective writes as follow $\max _{a_{1}(t), a_{2}(t)} \int_{0}^{T} e^{-\rho t} \bar{\pi}(t) d t+P[\bar{c}(T)-\bar{p} x(t)] \bar{\pi}$ subject to $\dot{c}=-a_{1}(t)$, $\dot{x}=f\left(a_{2}(t)\right), c(0), x(0)$ and T given. Using optimal control theory, the productive and commercial efforts are defined by $\psi_{a_{1}}=\frac{-P^{\prime} \bar{\pi}}{e^{-\rho t}}+\frac{1}{\rho}(1-$ $\left.\frac{e^{-\rho T}}{e^{-\rho t}}\right)$ and $\psi_{a_{2}}=f^{\prime}\left(a_{2}\right)\left[\frac{-P^{\prime} \bar{\pi}}{e^{-\rho t}}+\frac{\bar{p}}{\rho}\left(1-\frac{e^{-\rho T}}{e^{-\rho t}}\right)\right]$. Then, we can show that $a_{1}^{N C}(t) \leq a_{1}^{G C}(t)$ if $a_{2}^{N C}(t) \geq 0$. As for the gross cost contract, the shape of the effort path could be increasing, decreasing or U-shaped. 


\section{Appendix B: Specification Tests}

\begin{tabular}{|c|c|c|c|c|}
\hline Null hypothesis & Model & Test statistic & $\chi^{2}$ statistic $^{\dagger^{* *}}$ & Decision \\
\hline \multirow{5}{*}{$\begin{array}{l}\text { (1) Cobb-Douglas cost frontier } \\
H_{0}: \text { all cross effects null }\end{array}$} & 1 & 391.94 & 48.278 & Reject $\mathrm{H}_{0}$ \\
\hline & 2 & 324.78 & 48.278 & Reject $\mathrm{H}_{0}$ \\
\hline & 3 & 301.30 & 48.278 & Reject $\mathrm{H}_{0}$ \\
\hline & 4 & 259.44 & 48.278 & Reject $\mathrm{H}_{0}$ \\
\hline & 5 & 162.32 & 48.278 & Reject $\mathrm{H}_{00}$ \\
\hline \multirow{5}{*}{$\begin{array}{l}\text { (2) No inefficiency effects } \\
\mathrm{H}_{0}: \gamma \text { and all } \delta_{S}=0\end{array}$} & 1 & 577.49 & 10.501 & Reject $\mathrm{H}_{0}$ \\
\hline & 2 & 470.76 & 14.325 & Reject $\mathrm{H}_{0}$ \\
\hline & 3 & 457.55 & 16.074 & Reject $\mathrm{H}_{0}$ \\
\hline & 4 & 470.83 & 17.755 & Reject $\mathrm{H}_{0}$ \\
\hline & 5 & 449.82 & 22.525 & Reject $\mathrm{H}_{0}$ \\
\hline
\end{tabular}

$\dagger$ Unless otherwise stated, all tests of hypotheses are conducted at the $1 \%$ level of significance.

* In the case of the no inefficiency effects assumption (2), the generalized likelihood-ratio is asymptotically distributed as a mixed chi-square, see Kodde and Palm (1986). 